\title{
PENGEMBANGAN SISTEM INFORMASI DESA (SID) GUNA MENINGKATKAN GOOD GOVERNMENT DI DESA GONDOSULI KECAMATAN GONDANG KABUPATEN TULUNGAGUNG
}

\author{
Wahyu Nurvita Afnani ${ }^{\star}$, Neni Wahyuningtyas, Mohammad Pebrianto, Anif Fatimatus \\ Sholichah, Riski Nabila Gandi \\ wahyu.nurvita.1707416@students.um.ac.id
}

Prodi Pendidikan IPS, Fakultas IImu Sosial, Universitas Negeri Malang

Diterima 18 Agustus 2020, dipublikasikan 31 Oktober 2020

\begin{abstract}
Abstrak
Pengembangan Sistem Informasi Desa ini bertujuan meningkatkan good government di Desa Gondosuli Kecamatan Gondang Kabupaten Tulungagung. Alasan Desa Gondosuli dipilih untuk pengembangan Sistem Informasi Desa dikarenakan selama ini belum optimal sebagai media integratif dalam membangun desa. Metode pelaksanaan kegiatan pengabdian ini adalah dengan memberikan bimbingan teknis berupa penerapan pengisian data, serta evalusi secara langsung kepada perangkat desa. Program Sistem Informasi Desa akan dilauncing kepada masyarakat desa dengan cara sosialisasi melalui Rukun Tetangga atau Rukun Warga maupun karangtaruna. Hasil dari kegiatan pengabdian ini adalah perangkat desa mampu meningkatkan kualitas pelayanan publik berupa pengoperasian Sistem Informasi Desa Dengan baik. Sehingga masyarakat desa setempat dapat lebih mudah dalam melakukan pengurusan administrasi melalui Sistem Informasi Desa.
\end{abstract}

Kata Kunci: Good Goverment, Good Governance, Sistem Informasi Desa

\section{PENDAHULUAN}

Kabupaten Tulungagung secara administratif terdiri atas 19 kecamatan, 14 kelurahan, dan 257 desa. Sebagai wilayah yang memiliki luas wilayah yang relatif besar pentingnya pemerintah pusat mendukung desa untuk memiliki Sistem Infomasi Desa (SID) guna menciptakan pemerintahan yang baik atau good goverment. Hal tersebut juga menunjukkan bahwa banyak pemerintah daerah yang memanfaatkan e-government secara optimal untuk pelayanan publik. Walaupun pada penelitianpenelitian sebelumnya dinyatakan bahwa $85 \%$ implementasi E-government dinegara berkembang mengalami kegagalan baik dalam skala kecil maupun secara keseluruhan (Heeks, 2003).

Berdasarkan Undang-Undang ITE No. 11 tahun 2008 tentang Informasi dan Transaksi Elektronik, setiap lembaga dituntut untuk mengimplementasikan e-government dalam tata kelola pemerintah dan pelayanan publik. Hal tersebut juga diamanatkan dalam Inpres No. 3 tahun 2003 tentang penyelenggaraan tata kelola pemerintahan secara elektronis di Indonesia. Di Indonesia, desa merupakan bentuk pemerintahan administratif terkecil (Fitri \& Asyikin, 2015). Desa memiliki tugas untuk melaksanakan pelayanan kepada masyarakat yang berkaitan dengan penerapan e-government di Indonesia (Mayowan, 2016). Oleh karena itu desa dituntut dapat mengikuti perkembangan teknologi informasi dan komunikasi dalam mengelola data administrasi kependudukan desa.

Upaya pemerintah dalam melakukan pembenahan wilayah ditingkat paling rendah seperti desa menjadi salah satu prioritas yang perlu diperhatikan. Perbaikan sistem informasi akan membantu dalam pengembangan pelayanan prima kepada masyarakat, memberikan kemudahan

dalam mengakses informasi, dan pelayanan sesuai dengan keinginan masyarakat (Hidayatulloh \& Mulyadi, 2015). Sebagai daerah tingkat otonami daerah terkecil, desa merupakan bagian penting dalam menentukan keberhasilan pembangunan. Hal tersebut karena desa bersentuhan langsung dengan masyarakat, utamanya dalam pelayanan publik. Namun kenyataanya tuntutan desa akan egovernment berbanding terbalik dengan keterampilan aparatur desa yang justru rendah. Sistem pengelolaan arsip secara konvensional sampai saat ini digunakan memiliki resiko tinggi jika ada 
bencana alam seperti banjir dan kebakaran. Dengan demikian untuk membantu pelaksanaan pembangunan desa, diperlukan pendampingan SID yang akan disesuaikan dengan prioritas pembangunan daerah dan nasional (Kamim, 2019).

Berdasarkan UU Desa pasal 86 ayat 4, bahwa SID terdiri atas informasi data Desa, data Pembangunan Desa, Kawasan Perdesaan, serta informasi lain yang berkaitan dengan Pembangunan Desa dan pembangunan Kawasan Perdesaan. Pemerintah desa sebagai provider atau penyedia layanan SID yang sekaligus sebagai server yang mengatur serta mengontrol akses SID pada masyarakat. Maka dari itu SID merupakan suatu perangkat lunak yang dioperasikan dalam gawai dengan berbasis website. Hal ini dikembangkan untuk meningkatkan kualitas sumber daya manusia terutama dalam melek teknologi. Terdapat akun server yang dioperasikan oleh perangkat desa dan akun pengguna yang dioperasikan oleh penduduk desa (Dewi, 2011). Namun permasalahannya adalah kompetensi, kapabilitas dan jumlah Sumber Daya Manusia di Desa terbatas.

Perkembangan teknologi informasi dan komiunikasi saat ini telah berkembang sangat pesat, Bahkan teknologi informasi tidak dapat dipisahkan dalam kehidupan manusia saat ini (Wahyuningtyas \& Adi, 2018). Oleh karena itu, SID diharapkan akan berperan sebagai alat olah data dan informasi berbasis TIK yang akan menjadi salah satu rujukan dasar dan pemberi fungsi layanan di tingkat desa. Olah data yang dimaksud akan berjalan baik dalam ranah offline maupun online. SID dalam ranah offline diwujudkan dalam sebuah jaringan data dan informasi di kantor desa. Sedangkan dalam ranah online, SID terbangun dan terhubung dalam jaringan berbasis internet yang menghubungkan desa dengan dunia luar.

Desa Gondosuli merupakan satu dari 257 desa yang berada di wilayah Kabupaten Tulungagung. Desa Gondosuli berada pada kecamatan Gondang yang terdiri dari 2 dusun, 4 RW dan 14 RT, serta memiliki jumlah penduduk sekitar 2.438 jiwa (Badan Pusat Statistik Kabupaten Tulungagung, 2019). Berkaitan dengan penduduk khususnya pada kantor Desa Gondosuli, Kecamatan Gondang, Kabupaten Tulungagung teknologi system informasi desa sangat membantu dalam segala hal yang menyakut informasi pelayanan, dari prosedur pembuatan akte kelahiran, Kartu Keluarga (KK), hingga syarat-syarat nikah dan surat pindah. Desa Gondosuli saat ini adalah salah satu desa yang sudah memiliki Sistem Informasi Desa (SID) namun keberadaan Sistem Informasi Desa (SID) ini belum maksimal dalam pengelolaannya.

Untuk mewujudkan good government di pemerintahan desa Gondosuli, kecamatan Gondang Kabupaten Tulungagung sangat penting untuk mengembangkan Sistem Informasi Desa (SID) berbasis website. Pengembangan Sistem Informasi Desa (SID) di desa Gondosuli dimaksudkan untuk membantu perangkat desa mensosialisasikan dan meningkatkan kualitas pelayanan publik yang mudah sehingga akan terwujud good government dan membantu masyarakat desa setempat lebih mudah dalam mengurus adminstratif di desa.

\section{METODE}

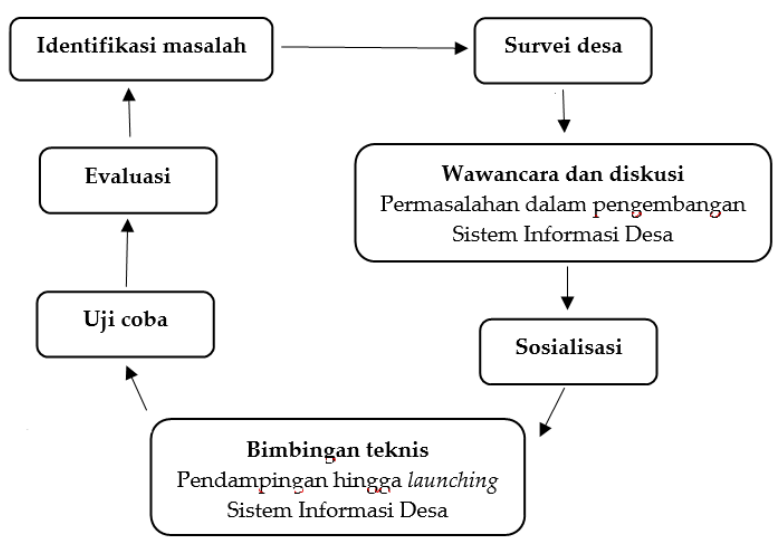

Gambar 1 Alur pelaksanaan pengembangan Sistem Informasi Desa 
Kegiatan pengabdian kepada masyarakat dilasanakan dengan melakukan pendampingan langsung kepada mitra pengabdian (Wiradimadja et al., 2019). Langkah awal yang dilakukan adalah identifikasi masalah untuk merumuskan apa saja yang akan dijadikan bahan perncangan Sistem Informasi Desa (SID) dan materi pelatihan yang tepat untuk aparatur desa dalam pengabdian ini. Selanjutnya tim pengabdian melakukan survey ke kantor Desa Gondosuli, Kecamatan Gondang, Kabupaten Tulungagung. Kemudian tim melakukan proses wawanacara dan diskusi dengan pihak perangkat desa untuk identifikasi permasalahan yang ada dalam pengembangan Sistem Informasi Desa (SID) di desa.

Dalam pengabdian ini selanjutnya melakukan sosialisasi kepada masyarakat setempat yaitu dengan mengundang narasumber dari BPD Kabupaten Tulungagung dengan materi penginformasian Sistem Informasi Desa (SID) kepada masyarakat desa setempat. Setelah terlaksananya sosialisasi selanjutnya dilakukan TOT bagi Tim Teknis dari aparatur desa dengan didampingi DPMD setempat. Selain itu dalam pengabdian ini juga diadakan bimbingan teknis, pembibingan ini dalam bentuk penerapan pengisian data, setelah kegiatan tersebut selanjutnya akan diadakan evaluasi guna meningkatkan program menjadi lebih baik kedepannya.

\section{HASIL DAN PEMBAHASAN}

Berdasarkan peraturan Bupati Tulungagung Nomor. 188.45/148/013/2015 tentang Pengembangan Kawasan Agropolitan dan Minapolitas Tulungagung 2015 bahwa Desa Gondosuli dinobatkan sebagai desa minapolitan. Artinya Desa Gondosuli menjadi desa penyanggah desa lain di Kecamatan Gondang, Kabupaten Tulungagung (Kurniawan, 2018). Konsekuensi dari pernyataan tersebut yaitu Gondosuli harus menjadi percontohan bagi desa lainnya. Maka dari itu penerapan SID dapat menjadi solusi adaptif pemerintah desa terhadap perkembangan teknologi dalam hal pemerintahan dan layanan publik.

Pelaksanaan pendampingan hingga launching ini merupakan bagian dari pengabdian mahasiswa yang dilaksanakan pada tanggal 02 Juli 2020, dengan kelompok sasaran perwakilan RT, RW, atau karangtaruna yang berasal dari setiap dusun yang ada di Desa Gondosuli Kecamatan Gondang Kabupaten Tulungagung. Pendampingan sistem informasi desa harus didukung dengan penguatan kapasitas sumber daya manusia yang dimiliki oleh pemerintah. Selain itu fasilitas penunjang yang dimiliki juga akan memberikan perbaikan dalam proses pelayanan melalui informasi (Sakir et al., 2019). Dari pendampingan tersebut telah dicapai hasil non-fisik berupa pengoperasian Sistem Informasi Desa (SID).

\section{Hasil Pendampingan Non-Fisik}

Tim pengabdian mahasiswa memberikan paparan materi penjelasan mengenasi Sistem Informasi Desa (SID) dengan pemanfaatan ketersediaan LCD yang ada di balai desa tempat pendampingan. Secara teknis pengabdian mahasiswa juga dibantu oleh mahasiswa yang sedang melaksanakan kelompok mahasiswa UM yang sekarang sedang melaksanakan KKN di Desa Gondosuli. Kemudian diteruskan dengan penjelasan dan pengoperasian cara menggunakan Sistem Informasi Desa (SID) pada peserta pendampingan. Pendampingan yang pertama yaitu pendampingan dari kepala Dinas Pemberdayaan Masyarakat dan Desa (DPMD) Kabupaten Tulungagung. Pada saat peserta pendampingan diberikan pendampingan SID tersebut, terlebih dahulu diberikan sosialisasi mengenai wilayah Desa Gondosuli yang terdiri dari beberapa dusun dan potensinya masing-masing oleh kepala desa.

Pemanfaatan Sitem Informasi Desa (SID) dilakukan dengan cara digitalisasi data-data desa untuk memberikan layanan bagi masyarakat dengan cepat, tepat waktu, dan sesuai kebutuhan. SID diharapkan dapat membantu mempermudah pemerintahan desa dalam proses pencarian ataupun mendokumentasikan data-data milik desa. Maka dari itu, SID dinyatakan sebagai suatu rangkaian atau sistem mekanisme, prosedur, dan pemanfaatannya. Sehingga SID dapat mengelola sumber daya yang dimiliki oleh suatu desa sesuai dengan tujuan SID (Nuryanto, 2019). Dengan menggunakan bantuan handphone yang dibawa oleh masing-masing peserta, terlihat aktifitas para peserta secara individu 
dengan aktif mengikuti pendampingan pengoperasian Sistem Informasi Desa (SID) (Gambar 1). Selama proses pendampingan masih terlihat adanya kesulitan dalam pengoperasian Sistem Informasi Desa (SID) dari beberapa peserta, sehingga masih diperlukan pendampingan secara individu.
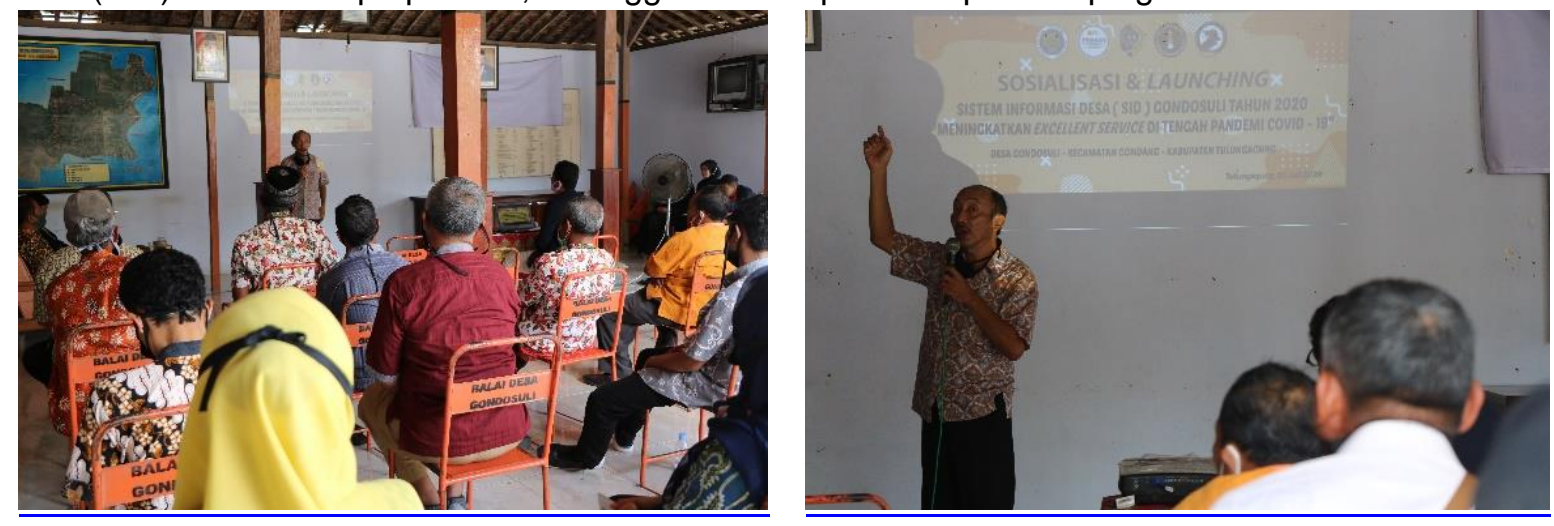

Gambar 2 Peserta sedang mengikuti pendampingan pengoperasian Sistem Informasi Desa (SID)

Tahapan kerja pengoperasian Sistem Informasi Desa (SID) yang dilakukan peserta yaitu: (1) ketua RT memberikan username dan pasword pada pemohon surat untuk bisa masuk pada layanan Sistem Informasi Desa (SID). (2) pemohon masuk pada layanan Sistem Informasi Desa (SID), kemudian pilih pada menu dengan tahap urutan dimulai dari layanan surat, cetak surat, pilih jenis surat, buat surat, isi form, eskpor dokumen, dan kemudian pilih cetak. (3) selanjutnya file surat akan dikirim ke admin untuk meminta nomor surat, tanda tangan, dan stempel. (4) setelah diterima, admin akan memproses surat yang diajukan pemohon. (5) pemohon mengambil surat di balai Desa Gondosuli setelah surat jadi.

Hambatan yang ada selama proses pendampingan pengoperasian Sistem Informasi Desa (SID) yaitu dibutuhkan waktu yang lama. Sedangkan tantangan yang dihadapi selama proses pendampingan yaitu berupa tingkat kesulitan yang terlihat pada peserta pendampingan. Tingkat kesulitan tersebut yaitu pada tahapan masuk layanan Sistem Informasi Desa (SID), serta pada tahap pemilihan berbagai macam menu yang disediakan agar bisa memproses surat yang ingin diajukan. Setelah pendampingan Sistem Informasi Desa (SID) dilanjutkan dengan penjelasan dan bimbingan teknis oleh mahasiswa pengabdian mengenai cara permintaan atau cara permohonan surat pada layanan Sistem Informasi Desa (SID) kepada peserta yang masih mengalami kesulitan atau kendala dalam mengoperasikannya. Dengan demikian pentingnya pendampingan Sistem Informasi Desa (SID) harus dilakukan yaitu agar masyarakat setempat dapat mengakses informasi perkembangan desa setiap saat sehingga akan lebih efektif dan efisien lagi. Artinya SID merupakan sistem yang tepat guna karena mempermudah proses pengelolaan data desa (Fitri \& Nugroho, 2017). Selain itu Sistem Informasi Desa (SID) dapat terus digunakan oleh perangkat desa untuk membagikan informasi ke masyarakatnya (Sakir, 2019).

Berdasarkan pemaparan tersebut, dalam program pendampingan kali ini tim pengabdian lebih banyak mengambil peran sebagai fasilitator. Pengembangan Sistem Informasi Desa (SID) dapat memberikan manfaat yang optimal dan menjadi sarana yang mempermudah masyarakat Desa Gondosuli. Dapat diidentifikasi dari beberapa hambatan dan tantangan saat proses pendampingan berlangsung pendampingan pengoperasian Sistem Informasi Desa (SID) yang sifatnya sementara belum dapat sepenuhnya turut mengembangkan Sistem Informasi Desa (SID) secara berkala.

Sistem Informasi Desa (SID) yang dilaksanakan di desa memiliki tiga fungsi dasar yaitu membantu desa dalam melaksanakan pelayanan publik, perencanaan pembangunan dan pemetaan situasi agar dapat mengambil keputusan secara cepat dan tepat (Hartoyo, 2016). Dengan demikian pendampingan perlu digunakan untuk pengembangan Sistem Informasi Desa (SID) yang memiliki kegunaan praktis tidak hanya sebagian masyarakat desa, birokrasi atau pemerintah pusat, namun bagi seluruh masyarakat. Pengembangan Sistem Informasi Desa (SID) Desa Gondosuli mengedepankan peran serta masyarakat agar mereka mengerti, ingin dan dapat menetapkan tujuan bersama sehingga 
merasa memiliki pusat informasi desa. Diharapkan dengan peran serta masyarakat, Sistem Informasi Desa (SID) yang dikembangkan bersama ini memberikan manfaat nyata bagi peningkatan kualitas hidup masyarakat Desa Gondosuli.

\section{KESIMPULAN}

Pertama, kegiatan pengabdian kepada masyarakat berupa pendampingan pengopersian Sistem Informasi Desa (SID) bagi perwakilan RT, RW, atau karangtaruna di Desa Gondosuli Kecamatan Gondang Kabupetan Tulungagung. Kegiatan pengabdian ini bersifat Abdimas (pengabdian mahasiswa). Lingkup materi pendampingan berupa bimbingan teknis: (1) admin diberikan bimbingan teknis mengenai Sistem Informasi Desa (SID) untuk memasukkan database berdasarkan kartu keluarga. (2) validasi dibantu tim pengabdian mahasiswa untuk mengecek ulang data yang sudah ada, menambah atau menghapus data kartu keluarga dengan berdasarkan situasi yang ada misalnya kematian atau kelahiran. (3) pembuatan username dan pasword. (4) pelaksanaan uji coba selama tiga hari dan setelahnya akan dilaksanakan evaluasi. (5) sosialisai dan launching program Sistem Informasi Desa (SID) melalui RT, RW, atau karangtaruna.

Kedua secara khusus, keberhasilan kegiatan ini meliputi: (a) perwakilan RT, RW, atau karangtaruna peserta pendampingan telah dapat menjelaskan konsep pengoperasian website khususnya Sistem Informasi Desa (SID). (b) perwakilan RT, RW, atau karangtaruna peserta pendampingan telah memahami cara pengoperasian Sistem Informasi Desa (SID) dengan baik dan benar. (c) perwakilan RT, RW, atau karangtaruna peserta pendampingan telah mampu memberikan arahan pada masyarakat yang ada di lingkungannya mengenai tahapan kerja pengoperasian Sistem Informasi Desa (SID).

Berkaitan dengan pelaksanaan pengabdian maka dapat direkomendasikasan dan disarankan hal-hal sebagai berikut: a) Rekomendasi teoritis, keberhasilan dalam pelaksanaan pendampingan Sistem Informasi Desa (SID) ini perlu disebarluaskan pada masyarakat lainnya diluar peserta pelatihan. Sosialisasi tambahan diperlukan untuk membangkitkan kesadaran seluruh masyarakat desa, sehingga penerapan program dan penggunaan SID dapat dimanfaatkan secara maksimal. Pelatihan sebagai strategi yang dilakukan dengan prinsip showing, telling, and doing dengan kerangka belajar sambil bekerja. Sehingga penerapan dapat dilakukan secara berkelanjutan; b) Rekomendasi praktis, dikarenakan Sistem Informasi Desa (SID) merupakan hal yang masih baru bagi masyarakat Desa Gondosuli maka sebaiknya pendampingan masih tetap dilaksanakan oleh aparat desa dalam jangka waktu yang lebih lama. Selain itu sosialisasi perlu dilakukan secara merata kepada seluruh lapisan masyarakat. Sehingga Sistem Informasi Desa (SID) akan benar-benar dapat digunakan secara berkelanjutan. Kemudian, untuk membantu mempermudah msayarakat dalam penggunaan Sistem Informasi Desa (SID) akan lebih baik untuk diberikan buku panduan pengaplikasian Sistem Informasi Desa (SID). Khususnya bagi masyarakat yang tidak mengikuti pendampingan.

\section{DAFTAR PUSTAKA}

Badan Pusat Statistik Kabupaten Tulungagung. (2019). Kecamatan Gondang Dalam Angka 2019. https://tulungagungkab.bps.go.id/publication/2019/09/27/16419644f5c5a40919c2c2d6/kecamat an-gondang-dalam-angka-2019.html

Dewi, A. S. (2011). The Role of Local e-Government in Bureaucratic Reform in Terong, Bantul District, Yogyakarta Province, Indonesia. Internetworking Indonesia Journal, 3(2), 49-56.

Fitri, R., \& Asyikin, A. N. (2015). Aplikasi Penilaian Ujian Essay Otomatis Menggunakan Metode Cosine Similarity. POROS TEKNIK, 7(2), 88-94. https://doi.org/10.31961/porosteknik.v7i2.218

Fitri, R., \& Nugroho, A. S. B. (2017). Pengembangan Sistem Informasi Desa Untuk Menuju Tata Kelola Desa Yang Baik (Good Governance) Berbasis Tik. Jurnal POSITIF, 3(2), 99-105. http://ejurnal.poliban.ac.id/index.php/Positif/article/view/429

Hartoyo, N. M., \& Merdekawati, I. (2016). Citalinuabdi: Upaya Membangun Sistem Informasi Desa

Yang Bermakna. Jurnal Komunikasi Ikatan Sarjana Komunikasi Indonesia, 1(1), 48-57.

http://www.jurnal-iski.or.id/index.php/jkiski/article/view/35 
Pengembangan Sistem Informasi Desa (SID) Guna Meningkatkan Good Government Di Desa Gondosuli...

Heeks, R. (2003). Most eGovernment-for-Development Projects Fail: How Can Risks be Reduced? (SSRN Scholarly Paper ID 3540052). Social Science Research Network. https://doi.org/10.2139/ssrn.3540052

Hidayatulloh, S., \& Mulyadi, C. (2015). SISTEM PELAYANAN ADMINISTRASI KEPENDUDUKAN DESA CANDIGATAK BERBASIS WEB. IT CIDA, 1(1), Article 1. http://journal.amikomsolo.ac.id/index.php/itcida/article/view/1

Kamim, A. B. M. (2019). Peran Organisasi Masyarakat Sipil dalam Proses Perintisan Sistem Informasi Desa di Kalibening Dukun Magelang Jawa Tengah [The Role of Civil Society Organizations in Pioneering Village Information System in Kalibening, Dukun, Magelang, Central Java]. Jurnal Politica Dinamika Masalah Politik Dalam Negeri dan Hubungan Internasional, 10(2), 183-203. https://doi.org/10.22212/jp.v10i2.1346

Kurniawan, H. D. P. (2018). Evaluasi Dampak Program Pengembangan Kawasan Minapolitan Berbasis Perikanan Budidaya Bagi Masyarakat Desa Gondosuli Kecamatan Gondang Kapupaten Tulungagung [Skripsi, Universitas Airlangga]. http://lib.unair.ac.id

Mayowan, Y. (2016). PENERAPAN TEKNOLOGI INFORMASI DAN KOMUNIKASI DI DESA (Studi Kasus di Kabupaten Lamongan). PROFIT: JURNAL ADMINISTRASI BISNIS, 10(1), 14-23. https://doi.org/10.21776/ub.profit.2016.010.01.2

Nuryanto, A. (2019). Keberhasilan dan Dampak Penerapan Sistem Informasi Desa dalam Perspektif Actor Network Theory (Studi Kasus di Desa Ngumbul Kabupaten Pacitan). Seminar Nasional GEOTIK 2019. http://publikasiilmiah.ums.ac.id/handle/11617/10798

Sakir, S., Rahmatullah, A. S., \& Sarofah, R. (2019). OPTIMALISASI SISTEM INFORMASI DALAM MENINGKATKAN PELAYANAN PUBLIK DI DUSUN TEMANGGUNG, JETIS, SAPTOSARI, GUNUNGKIDUL. Warta LPM, 21(2), 1-5. https://doi.org/10.23917/warta.v21i2.6567

Wahyuningtyas, N., \& Adi, K. R. (2018). Digital Divide Perempuan Indonesia. Sejarah dan Budaya: Jurnal Sejarah, Budaya, dan Pengajarannya, 10(1), 80-88. http://journal2.um.ac.id/index.php/sejarah-dan-budaya/article/view/1533

Wiradimadja, A., Kurniawan, B., \& Sukamto. (2019). PELATIHAN DAN PENDAMPINGAN PENYUSUNAN PTK (PENELITIAN TINDAKAN KELAS) BAGI GURU IPS SMP/MTS MALANG RAYA. Jurnal Praksis Dan Dedikasi Sosial (JPDS), 2(1).

Undang-Undang nomor 6 tahuun 2014 tentang desa.

Undang-Undang ITE No. 11 tahun 2008 tentang Informasi dan transaksi elektronik dan amanat Inpres No. 3 tahun 2003 tentang penyelenggaraan tata kelola pemerintah secara elektronis di Indonesia. 